Original Research Paper

\title{
Healthcare Experiences of Zabbaleen Women in Cairo, Egypt
}

\author{
Andrea Fortson Knopp \\ James Madison University, 820 Madison Drive, Harrisonburg, VA 22807, USA
}

\author{
Article history \\ Received: 10-02-2015 \\ Revised: 12-03-2015 \\ Accepted: 28-04-2015 \\ E-mail: knoppaf@jmu.edu
}

\begin{abstract}
The current political instability in the regions of North Africa and the Middle East threaten the safety of disenfranchised, vulnerable populations and the knowledge of health determinants in these people groups. Gender roles and cultural norms of the region place women in a marginalized position resulting in isolation and disconnection from society and the information or resources regarding healthcare. The women of the Zabbaleen community are a unique population in Cairo, Egypt with multiple factors known to contribute to inequities in healthcare. This study reveals barriers that affect healthcare related to issues of cultural behaviors and social determinants of health for the Zabbaleen women. The results provide insight into the perceived and actual barriers to health the women experience. This study reveals information critical to developing interventions in healthcare delivery and services during tumultuous times and future peaceful times. A qualitative constructivist design with personal interviews, participatory observation and field notes was used for this study. Internal barriers of cultural norms of gender, religion and isolation alongside external factors of environment, unique economic conditions and health resources shape the women's experiences.
\end{abstract}

Keywords: Egypt, Women, Healthcare, International

\section{Introduction}

In his recent book, Heirs to Forgotten Kingdoms, Gerard (Russell, 2014) reminds us that many influential civilizations are found in the historical minority cultures of the Middle East. Insecurity and distrust between warring factions magnify weaknesses in these countries' infrastructures while driving marginalized people groups further into the socio political determinants that disenfranchise them (Russell, 2014). The current political instability in the regions of North Africa and the Middle East threaten the safety of disenfranchised vulnerable populations and the knowledge embedded in these people groups. At risk is the continuation of their traditional practices and beliefs regarding health and illness.

Women of minority populations in particular are more vulnerable during crisis and are targets for violence, poor food supply, decreases in income and access to heath care (Palmar and Zwi, 1998). Due to sweeping changes in Egypt caused by the Spring Revolution of 2011, political unrest exists resulting in distrust of acting leaders. Daily commerce and activities of living are compromised by frequent riots since June of 2013 when General Sisi took over after Morsi, the freely elected president, was removed and imprisoned.
Government funding of subsidies such as gasoline, energy and food have dried up (Tamimi, 2014). Limited resources increase the risk of violence to the underserved while strengthening those with social and monetary power.

One of the at risk populations in Egypt particularly during times of unrest are the Zabbaleen who are Coptics living in Cairo (Mahmood, 2012). To be Coptic is to be a part of one of the earliest monotheistic faiths tolerated by early Muslims. The Copts are believed to be part of the indigenous population ethnically descended from the Egyptian Pharaohs because their language is phonetically similar to the language of ancient Egyptian hieroglyphs. The term "copt" is the Arabic version of Egypt, which was used to refer to Egyptians (Hasan, 2003). A blending of Pharaonic beliefs and early legends associating Isis and the Virgin Mary are evident in early temple art and writings from the 4th century (Kamil, 2002; Hasan, 2003). Historically, it is recorded that Egypt was largely christianized by St. Mark during Constantine was converted in the early 4th century prior to the Arab Muslim invasions in the 7th century (Mahmood, 2012; Samaan and Sukkary, 1978; Kamil, 2002; Hasan, 2003).

Early in Islam history, Mohammed urged Muslims to treat the Copts as if they were family. Unfortunately, 
Islamic religious leaders later required the Copts to pay a high tax for not converting to Islam as well as pay higher income and property taxes. This relative good will lasted until the 11 th century when the religious rulers issued laws to destroy churches, confiscate land and abolish Coptic holidays. Copts were also required to wear distinguishing apparel with heavy wooden necklaces. From that point, Copts tended to separate themselves from the general population, intermarrying and establishing their own communities for safety, cultural practices and socialization (Samaan and Sukkary, 1978; Hasan, 2003).

Approximately fifty years ago, a group of Coptic farmers migrated to Cairo due to socio-economic difficulties and religious discrimination in Upper Egypt (Thomas et al., 2006; Ibrahim, 1996). The community settled in Mokattam (or Moqattem) the site of an old quarry in the eastern section of Cairo. As squatters, the families would randomly settle on a plot on land in the area building tin houses and pig pens (Assad and Garas, 1994; Assad, 2001). The farmers began making a living by collecting garbage through the "wahiya" who were the mostly male service providers to the families of Cairo (Assad and Garas, 1994; Assad, 2001). The service workers interacted with the residents collecting a fee for the garbage removal acting as a middleman. The "wayiha" would arrange for the farmers to pick up the garbage but would not share the collected fees. In fact, the farmers also paid the "wahiya" to have access to the garbage. The farmers were not allowed to interact with the residents as they were considered unclean due to the cultural practice of raising pigs: therefore, necessitating the "wahiya" middleman. From the activity of collecting garbage, the community received its name "Zabbaleen", which is translated from Arabic as "garbage people" (Fahmi and Sutton, 2006; Assad and Garas, 1994).

Currently, an estimated 40,000 to 60,000 Zabbaleen Copts live in the poor urban area of Mokattam. The men typically collect the garbage storing it inside the home in the bottom floor or immediately outside the door. The women sort through the garbage to find leftover food, recyclables and fodder for their animals (See Fig.2). Even with recycling and resale of production from the garbage the Zabbaleen live in the lowest 4\% of Egypt's socioeconomic scale living on an estimated income of less than 20 USD [US dollars] a month (El-Jesri, 2008). Living with and sorting the garbage results in risks of injury from sharp objects, respiratory disorders and high rates of hepatitis (Kovach, 2003; Datta, 1995).

Social conditions of the Coptic Zabbaleen women may even be a fundamental cause directly affecting health by influencing access, resources and education. Kharboush et al. (2005) investigated women's health status and gender differences in health. Health problems were reported more frequently in women than men but women received less care. Kharboush et al. (2005) also found evidence of cultural gender preferences in that mothers overlooked health problems of daughters but focused on health problems of sons.

Mistrust of healthcare providers, lack of national screening programs, early onset of sexual activity and low socioeconomic class affected women's reproductive health (Abdel-Hady et al., 2006; Sallam et al., 2001a; $2001 \mathrm{~b}$ ). Other reproductive health issues affected by social conditions include early age of sexual intercourse, young maternal age at first birth and limited options for family planning methods (Glasier et al., 2006; Talaat et al., 2004; Sallam et al., 2001a; 2001b).

Wariness of government health programs also arise from the high rates of HCV that are attributed in part to a national campaign to treat schistosomiasis, or bilharzia, a helminthic infection transmitted from snails that flourish in the canals and tributaries of the Nile in the Delta regions (Rao et al., 2002). The campaign, called Parenteral Antischistosomal Therapy (PAT), lasted 15 years, from 1965 to 1980 focusing on the rural Delta regions and southern regions in Egypt where bilharzia was most prevalent and where a large portion of Copts lived (Roberts and Levitt, 2000; Frank et al., 2000; Hyams et al., 1987). Studies indicate that contaminated reusable needles and syringes used in this government campaign resulted in transmission of both Hepatitis B and C (MacKeen, 2003; Roberts and Levitt, 2000; Hyams et al., 1987; Rao et al., 2002). Sixty eight percent of patients with Hepatitis $\mathrm{C}$ received schistosomiasis treatment during the PAT campaign (Rao et al., 2002). Even though women were not given the treatment as often as men in the PAT campaign, the prevalence of HCV among Egyptian women is estimated at 7 to 23\% (Abdel-Aziz et al., 2000; Nafeh et al., 2000; Deuffic-Burban et al., 2006; Michael Atef, personal communication, March 17, 2008).

Gender roles, the cultural norms, educational level and socio-economic status clearly affect women's health issues in Egypt. Under use of health services is attributed to lack of monetary resources, poor perception of quality of care at government facilities, perceived attitudes of health workers and lack of female physicians (Kamel et al, 2003; Talaat et al., 2004; RoudiFahimi, 2006; Khattab, 1992; Kharboush et al., 2005; Sallam et al., 2001a; 2001b). Under treatment and high infection rates were particularly noted in the urban and rural poor (Kharboush et al., 2005; Talaat et al., 2004; Kamel et al., 2003). Again, poverty contributed to under treatment, but women were found to be referred less often for diagnostic and therapeutic interventions, receive less aggressive testing and treatment compared to men (Kharboush et al., 2005; Kamel et al., 2003; Sallam et al., 2001b). Lack of access to female physicians and lack of access to various types of contraception contributed to the barriers to women's healthcare use (Ali, 2001; Sallam et al., 2001b). It is also noted that women who 
were able to see a provider were referred less frequently, had fewer diagnostic tests and less aggressive treatment than male patients. Health disparities exist for women as compared to men in using health resources, receiving health education and accessing care even when the resources were available. Modern healthcare resources may be available but not used by the women due to negative experiences and/or cultural issues.

Few studies address Hepatitis C Virus (HCV) in Egyptian women even though Egypt has one of the highest prevalence of HCV in the world (WHO, 2014; Deuffic-Burban et al., 2006). Risk factors associated with $\mathrm{HCV}$ in pregnant women were low socioeconomic status, advanced age, history of PAT, history of blood transfusion and use of injections for treatment of illness (Stoszek et al., 2006; Medhat et al., 2002). Interestingly, men with HCV positive wives were much more likely to convert than sero-negative women with seropositive husbands.

Any Egyptian proverb, "I went to put kohl on her and I blinded her" epitomizes the history of Egyptian women's experiences in health. In the earnestness of trying to provide aid, such as PAT program, damage is done. Ramifications of those actions spread distrust through the subsequent experiences of women in general and Zabbaleen women in particular.

\section{Materials and Methods}

Constructivist methods with an interpretivist approach explore meanings and experiences based on the idea that people interpret their world and this interpretation is constantly changing (Williamson, 2006). Hermeneutical and dialectical processes uncover meanings to reach an understanding of an experience, in this case related to healthcare (Lincoln and Guba, 2011; Cohen et al., 2000). This research focuses on the voice of the participants and shares control of the research process between the researcher and the participants essential to early work in a vulnerable community (Al-Saggaf and Williamson, 2006; Williamson, 2006; Lincoln and Guba, 2011). The essence or intrinsic nature of the women's experience in light of the social issues is richly explored using this approach.

There is limited accessible medical research literature available or translated in English in medical databases about Zabbaleen women's healthcare experiences and social constructs. With that in mind, an ethnographic approach with constructivist methodology is the most appropriate design to describe and interpret the healthcare experiences of the Zabbaleen women from the context of their culture. The use of a qualitative format for this research also gives opportunity for the women to have a voice in a culture where women are suppressed.
Because Zabbaleen women face gender, religious, economic and ethnic prejudice, their stories resonate with other women in similar situations. The importance of this work lies not only in its contribution to knowledge but also in its contribution to the women and the value of their narratives.

\section{Ethical Considerations}

Prior to initiating the study, an intensive IRB review as conducted to ensure the rights of the participants in an international setting. Documented permission was also obtained from the acting leader of the community, Father Samaan, after written and personal communication. All data were unidentified and protected per protocol. Participants were voluntarily consented with verbal and written information with the use of an interpreter.

\section{Sample}

Participants were selected by convenience sampling, walking through the neighborhood and by word of mouth. Criteria for participation were female, between the ages of 19 and 45, married or unmarried. Women of this age group were selected because they are developmentally past adolescence and too young to have to deal with issues of aging and most chronic diseases of the aged. Pregnant women were excluded because of the specialized care given during pregnancy. Key contacts were two women, a Coptic woman from the Zabbaleen community and a native English speaker, who had lived and worked in the area for several years.

\section{Setting}

Thirteen women participated in interviews that took place at church offices, in homes and in the streets of Mokattem, Cairo. Women were approached on the street while they sorted garbage, in the church plaza or in storefronts where they congregated. During these interviews, other women and men in the street would sometimes participate in the conversation, producing a more social interview setting.

\section{Data Collection}

Data were collected through semi-structured interviews, more informal interviews with consecutive interpretation and observations and field notes recorded in a journal during data collection. Interview data were recorded digitally in Arabic and transcribed into written Arabic. The written Arabic was translated into written English, crosschecked and translated back into Arabic by bilingual translators and transcribers in Egypt for validation. Immersion in the Zabbaleen culture, observations and interviews reveals patterns leading to interpretation of social behaviors.

In-depth semi-structured interviews using probe questions were conducted in which participants were 
asked to describe their health care experiences using consecutive translation. Consecutive translation is real time or immediate interpretation that allows immediate clarification. The researcher asked an interview question, the interpreter translated to the participant and as the participant responds, the interpreter translated the response to the researcher. When the response is completed and understood, the researcher continued the interview either based on the response or asked another question. Transcripts were made from the recordings by the translator in Cairo and verified by the consultant in Middle Eastern language. The audiotapes in Arabic were transcribed into written text in Arabic and then the written Arabic text was translated into English text. Interview transcriptions were checked for accuracy by listening to the Arabic tape recording while reading the English transcription. The text format was imported into the qualitative program NVIVO 7 for analysis.

Observations were made at the participants' homes and other places where the participants met the researcher. Field notes were taken during interviews and everyday interaction in the community and Cairo in general. Field notes contained records of informal conversations, interpretations, reflections and ideas for additional information to be collected. Specific data about health providers was not gathered, only impressions and statements by women participants.

\section{Data Analysis}

There are five steps described by Fife (2005) and Emerson et al. (1995) to use when analyzing data in ethnographic research. Following these steps, the data was (1) read several times by the researcher to become familiar with the text, (2) grouped into meaningful segments, (3) read again to reveal categories, (4) grouped around commonalities, patterns and relationships based on the categories and (5) developed into themes about the healthcare experiences of the women from the categories. Inconsistencies or breakdowns will also occur in the grouped categories. Inconsistencies were used to clarify the categories and provide "emic" richness to the data (Fife, 2005). The inconsistencies are part of ethnographic constructivist research in a naturalistic setting with individuals. The breakdowns also directed the researcher to other possible area of research.

In the last step of analysis, themes were developed describing the experiences of the women in the context of healthcare. Themes were based on categories that have the most supportive data (Emerson et al., 1995). Recurring categories were the basis for over-reaching themes. Theme development was based on patterns and categories that were significant to the participants as noted by repetition and recurrence. The Zabbaleen women identified important or significant pieces of data in the interviews or may repeat certain observable behaviors that are identified as important. Resorting field notes around the themes was useful in uncovering relevant or related categories with data that was appropriate to more than one theme. From the themes, a focused interpretation of the healthcare experiences of the Zabbaleen women resulted.

\section{Results}

Health experiences for Coptic women in Egypt are influenced by gender roles that deter seeking healthcare, focus on the priority of men and limit reproductive rights. Cultural practices and norms of delaying healthcare and keeping silent about symptoms of illness negatively affect women's health experiences. Socioeconomic status and education were often synergistic factors impeding women's access to healthcare, knowledge about symptoms of illness and delay in treatment.

Zabbaleen women suffer further inequalities due to societal norms of the area related to gender in addition to the other factors of inequalities in this population. In the Zabbaleen community, females are disadvantaged early in life due to low literacy, low education levels and limited opportunities. Limited spaces in school rooms are given preferentially to male children. Girls are also not encouraged to focus on academic study as their role is to marry and be fecund. Many young girls will discontinue their education unless there is strong family support.

Women tend to marry young and start families; a common practice in both the culture and in impoverished populations further impeding their education. Early motherhood adds to their marginalization and isolation. Women are responsible for the care of children, tending livestock as well as the maintenance of the household. Social stigma related to their employment, the stench of garbage, expectations in the home and lack of support for education where they live isolate the women in the community even more.

The women in this study describe several barriers that affected their healthcare related to issues of cultural behaviors and social determinant of health. The barriers were as personal as family status within the Zabbaleen community itself and as broad as access and availability of government clinics. The issues of gender and societal norms are outside forces acting upon the women impeding their ability to obtain healthcare. However, internal forces are generated from the religious and cultural beliefs that impact the women in a way that generates a complex maelstrom of barriers.

\section{External Factors}

\section{Environmental Barriers}

The Zabbaleen community is founded in a section of Cairo upon the only mountain in the area. The sandy stone buildings rise up four to five stories with unfinished upper stories due to high taxes for completed 
buildings. No spacing between the buildings limits the airflow in the streets which are lined with the garbage strewn in the streets from the trucks and carts returning from the city and the recyclables that are packaged up to be sent away. Animals roam free in the streets along with the rodents. Cattle and pigs are housed on the unfinished roofs. Waste from the animals above and below mixes in the stagnant air along with the smoke and particulates from the burning of materials and grinders for the plastic recyclables. Sanitation is available in the upper stories of the houses but is limited on the lower floors (See Fig. 1).

Living arrangements in the buildings are based on family status. Males with families have priority to upper levels with better water, sanitation and air. Widows without male support or ostracized individuals live on the lower floor with poor sanitation, water access and amongst the actual garbage that is dumped inside the house. Needless to say, health status decreases proportional to the floor level of habitation. Respiratory, diarrheal and nutritional illness are the most common morbidities related to environmental issues in the area.

\section{Provider Barriers}

In addition to the environmental barriers to the women and the community of the Zabbaleen in general, there are the health provider barriers that affect the women's healthcare. The lack of providers in the Mokattem region along with the poor provider to /patient ratio in Egypt overall results in clinics that are available only one day a week for specific health problems. The gynecologist for the community was only available one or two days a week. The preference for a female provider even further prevented ease and access to health care. These issues overlap with the environmental issues in compounding the lack of access to providers for illness caused by the environment and the systems lack of resources for the population, magnified by in the disadvantaged population of the Zabbaleen.

Within the actual community of the Mokattem where the Zabbaleen live there is one government clinic staffed by a physician just outside the community wall. The physician is typically male and of the Muslim faith. As the Zabbaleen are of the Coptic Faith there is some reluctance to be seen by a provider at the government clinic and there is a fee for services.

The Coptic church has a private church- sponsored clinic inside one of the church compounds in the community that includes a small eight-bed hospital with separate wards for men and women. One general or one specialty physician of the same religious beliefs is in attendance on a rotating basis on various days. If care is needed on a day that the appropriate physician is not in residence then it is necessary to go outside the community for care that would include the cost of a taxi ride, doctor, clinic and medication fees. Tips needed for the various services, buksheesh, increases the cost to beyond the economic abilities of these families.

\section{Socioeconomic Barriers}

As mentioned earlier, the population is in the lower $4 \%$ of the nation's impoverished people with an annual income of 175 United States Dollars (USD) (980 Egyptian Pounds [LE]). Consequently, few residents own a car in Zabbaleen. If care outside the community clinic or hospital is needed, transportation is difficult and costly. Microbuses or taxis cost about 10-20 cents (15LE) per one-way trip and a family member may have to pay tips to healthcare workers as well as stay all day with the patient to help with care. Females are expected to marry to bring income into the family as well work in the sorting of garbage. Illness impedes both of these goals reducing the ability to bring in needed financial resources.

Influx into Egypt and particularly Cairo by refuges from Sudan, Somalia and Chad has stretched the limited resources of housing, employment and healthcare and relief assistance provided by the government. Food shortages of bread and rice, which are staples in the diet, have caused further economic stress as well as riots and violence in the area. The Zabbaleen faced another major economic setback when the government slaughtered all their pigs over concerns about swine flu, wiping out a major source of food, income and consumption of biodegradable waste by the animals. The decision was done in spite of international disapproval and lack of scientific evidence. Families tend to hoard the limited resources they have and maximize use of the trash coming in for extra food.

\section{Internal Factors}

\section{Cultural Barriers}

Tied to the incident of slaughtering the pigs of the Zabbaleen is a long history of cultural and religious prejudice reported by the Zabbaleen. Zabbaleen Copts are a segregated minority because they practice an orthodox form of Christianity rather than Islam; they believe they are ethnically descended from the Egyptian Pharaohs rather than from Arabs evidenced by differences in cultural customs that include eating pork, celebrating different holy days and not requiring women to cover their heads.

The stench of the community from the waste and burning of the trash inhibits social interaction with those outside the community. Even taxi drivers are reluctant to take passengers in and out of the community due to the smell and the narrow trash filled dirt roads. This in turns promotes outsiders to view the Zabbaleen in a negative manner due to their living conditions and socioeconomic status culminating in isolation for the women and community as a whole. Social interaction with strangers is avoided and outsiders must prove worthy of trust.

\section{Gender Barriers}

Men were given priority when healthcare was needed in a family. Men were often seen before women and 
given different treatment and information based on their gender. In receiving treatment for Hepatitis $\mathrm{C}$, men more often sought and received treatment than women due to cost and time involved in the treatment regimen.

A young female is expected to have a dowry. If jewelry and gold is sold for treatment and medical costs, the female's chances of marriage are greatly decreased, increasing her burden upon the family. Lady D's interview takes place with her adolescent daughter and cousin. The mother was more than willing to discuss difficulties related to illness in their daily life. Even though the mother was the one positive for HCV, other members of the family felt the impact:

Lady D: We trust God... We suffered. We were suffering and having lots of expenses (for healthcare) since five months. We cannot buy the trousseau of her sister. Yesterday we were about to sell her gold... if God wills, she will get married before getting her final grades (from school)

Illness also affects a sibling's ability to marry well lowering the social standing of the family in the community. If it is known a daughter or sibling is ill the family struggles to find acceptable arrangements with ramifications that last for years.

Time taken away from family responsibilities such as sorting the garbage, meal preparation and care of the children is also a deterrent for the women to obtain healthcare. Time to travel to and from clinics reduces time for the other responsibilities while impairing the production of resources for the family. Lady N, a 40 year-old woman with HCV who had several daughters and no sons, worried about having enough to support her children and have them marry. She also wondered who would care for her as she got older; she talked about her concerns in her prayers. She said:

I am praying and asking God, saying to Him: God don't let anyone experience the pain I have been through and the fatigue that wore me down. I am pacifying myself with the word of God and I can't go to the church. I don't go out. I can't work

\section{Religious Barriers}

As a religious minority, restrictions are placed on the Zabbaleen Coptics ability to worship freely outside their community. Therefore, the Coptic Church plays a vitally important role in the everyday lives of the community in preserving their faith and support of each other. The Copts continue to practice their faith in ways very similar to the early traditions of the church and the original Coptic language dating back several centuries is still spoken in certain church services. Almost all the children receive a tattoo of a cross on their left hand between the thumb and forefinger or on the underside of the wrist to identify them as Copts. This readily visible marking make it difficult to find jobs outside the community and places them under greater scrutiny in the workplace.

The mistrust of outsiders and limited access to outside healthcare turns the women to traditional beliefs and health practices as initial treatments. These practices include traditional pharonic uses of the blue kohl lining the eye to ward off diseases, black bread feed to dogs to avert illness and san from holy ground to cure diseases. Distrust of government backed health programs also cause the women to retreat to well known cures taught by the elders. Teas and herbal remedies are used prior to seeking healthcare and to the exclusion of more modern medicine.

Religious dogma from the church promotes belief that their faith will heal them of a disease; if not, then God has a purpose for their illness. An internal conviction that an illness is part of a larger design from their deity inhibits the women from pursuing more aggressive care or even mentioning being sick. Lady O keeps three of her young grandchildren at her upper apartment since she could not work an outside job because of her HCV. She also has arthritis in her knees and did not move without pain. Her husband had passed away years ago after suffering from what she described as a terrible mental illness. When she talks about her health experiences, she sums up her ideas on health in this quote:

Lady O: We are poor Lord, whatever you do; we are in your hands Lord. We don't complain about anything

In a close-knit society, privacy issues create a sense of shame. Everyone knows her neighbors personal affairs. Women who do not attend religious services or participate in the social structures of the community are judged as being poor in faith. Lack of money and resources for treatment limited the possibility of receiving care in another location that would allow more discretion:

Lady N: Believe me; all what my friends tell me is hurting... they say you are afflicted. People are afflicted by one adversity but you have four. When I go with my husband and children to take the treatment, when our friends go with us, those who take it say you are afflicted. People are normally afflicted by one adversity but you have four. People say things that hurt

In turn the women often delay seeking healthcare multiplying the consequence of the illness when treatment was sought. One of the participants Lady H, described what HCV had done to her family. 


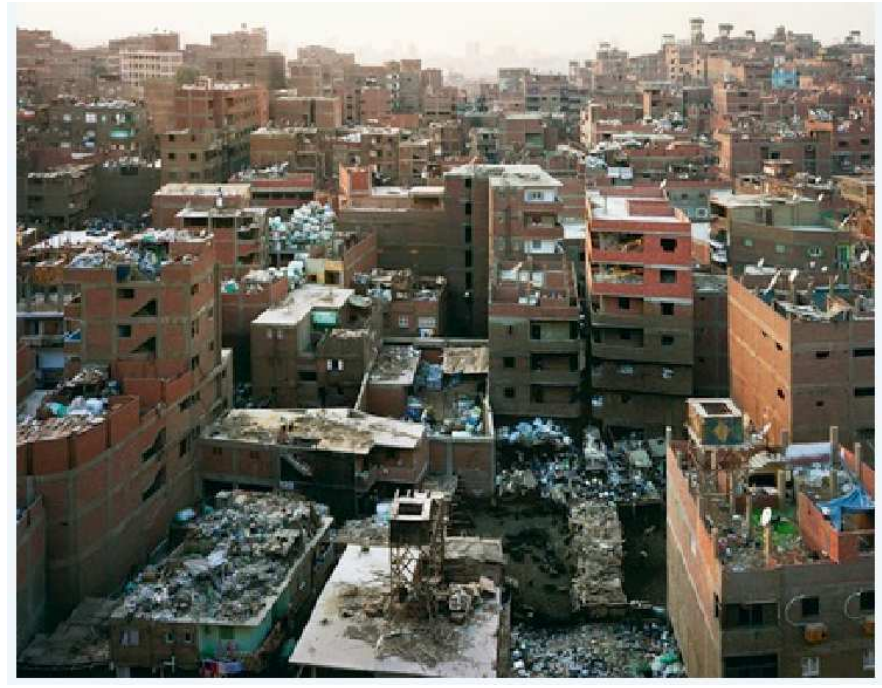

Fig. 1. Overview of zabbaleen community

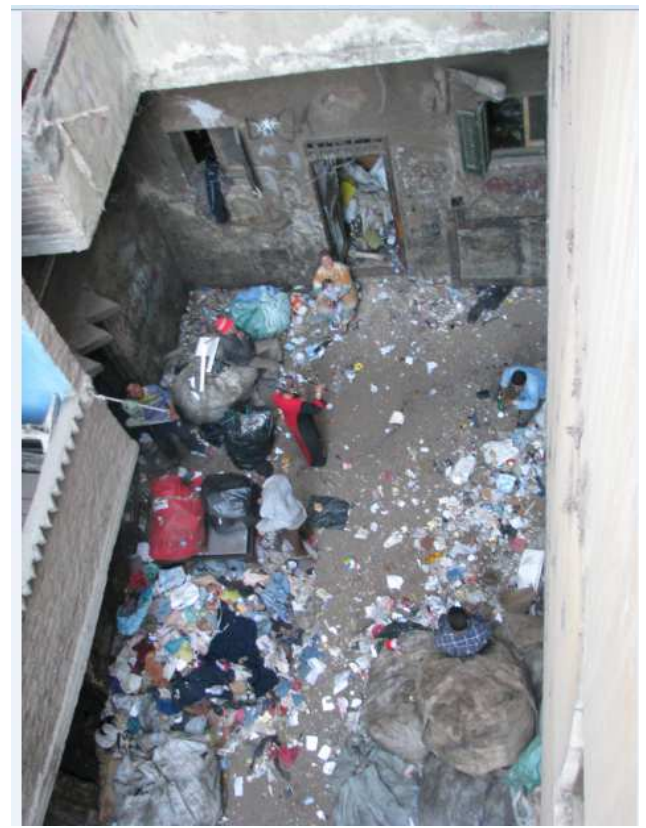

Fig. 2. Women sorting garbage in courtyard of home

\section{Discussion}

This discussion focuses on the social determinants that play into the health experiences and survival of the Zabbaleen women.

Health disparities exist for women of this study. Women do not access the health resources due to negative experiences or cultural issues. Distrust based on historical events of government agencies mistreating the public during the treatment program for schistsomiaisis prevents women from using health resources, receiving health education and accessing care even when the resources are available. In addition, political unrest and episodic violence deter women from seeking healthcare. Increased levels of fear reduce individual appropriation of care. Attacks in the streets, verbal abuse, riots, unequal treatment in clinics or complete lack of treatment reinforce the adage "I went to put kohl on her and blinded her". Until the negative associations are alleviated to a level of comfort and trust, women will avoid modern health resources and typically use more traditional or cultural practices.

Inequities for Zabbaleen women in Egypt were influenced by gender roles that deter seeking health care, a focus on male priority in healthcare and maintenance of security in marriage relationships. Cultural practices and norms of delaying healthcare and keeping silent about symptoms of illness negatively affect women's health experiences as importance is on the social relationship and standing in marriage. If health issues potentially jeopardize the significant relationship with the male spouse, then it ceases to have priority.

Socioeconomic status and education are often synergistic factors impeding women's access to healthcare, knowledge about symptoms of illness and delay in treatment. Poverty's influence can be noted in the inability to recognize illness as well as the lack of understanding of what to do with the illness. Treatment limitations due to lack of income and education include monetary resources to see a provider and obtain medication. Options are also limited by the knowledge of standard treatment or use of traditional cures and herbs for common illnesses.

Without evidence of change in the prevailing political forces, distrust of government sponsored clinics and health programs continue. Women are not willing to be seen or treated by government "outsiders" and prefer to use traditional health practices. Some practices are based in rituals and cultural beliefs but are still preferred over western type healthcare. 


\section{Conclusion}

These women are a microcosm of the blending of cultural norms and beliefs among women of a minority community living in an Islamic majority that impede access to health care. Overreaching these social determinants is the greater disruption of political instability. In times of unrest, social norms that determine role and behaviors are upended leading to further disruption in health, class, gender, power, education and environment. The current political strife magnifies the negative determinants of health and increases the negative associations breeding fear.

Program development in Egypt is not a priority at this time. The country needs to stabilize resources, increase security while continuing to decrease barriers to health and other health issues in this population. Sanitation, water supply, other diseases and economic development will most likely take a back seat to more pressing priorities. When the political picture is clearly established, health programs need to take into consideration the distrust from previous political actions and the cultural/spiritual issues that make this population unique.

In times of turmoil, the likelihood of positive change for the population as a whole in Egypt is limited. Time and resources whether backed by military or fundamental religious rule are diverted to political advancement and military power. Therefore, Coptics of the Zabbaleen are at even greater risk due to the increased unrest in Cairo, mob riots and isolation. Attention needs to be given to the health history of the Zabbaleen in order to protect the population and its practices Awareness of social deprivations and barriers to their health will allow for future programs of health to address the complexities highlighted in this research while bridging the gap of mistrust.

\section{Acknowledgement}

The author declares no financial support or relationships that pose a conflict of interest.

\section{Funding Information}

There are no funders of this manuscript.

\section{Ethics}

The author has ensured complete anonimity of all participants in the study. All data were unidentified and protected per protocol.

\section{References}

Abdel-Aziz, F., M. Habib, M. Mohame, M. AbdelHamid ans F. Gamil et al., 2000. Hepatitis C virus infection in a community in the Nile Delta: Population description and HCV prevalence. Hepatology, 32: 111-115.
Abdel-Hady, E., M. Emam, A. Al-Gohary, M. Hassan and M.K. Farag et al., 2006. Screening for cervical carcinoma using visual inspection with acetic acid. Int. J. Gynecol. Obstetrics, 93: 118-122.

Ali, M.M., 2001. Quality of care and contraceptive pill discontinuation in rural Egypt. J Biosoc Sci., 33: 161-72. PMID: 11284624

Al-Saggaf, Y. and D. Williamson, 2006. Doing ethnography from within a constuctivist paradigm to explore virtual communities in Saudi Arabia. Qualitative Sociol. Rev., 2: 5-20.

Assad, C., 2001. Empowerment as kaleidoscope: A comprehensive empowerment approach for young women squatters in Cairo. J. Biosocial Sci., 33: 161-172.

Assad, M. and N. Garas, 1994. Experiments in Community Development in a Zabbaleen Settlement. 1st Edn., American University in Cairo Press, Cairo, Egypt, pp: 70.

Cohen, M.Z., D. Kahn and R.H. Steeves, 2000. Hermeneutic Phenomenological Research: A Practical Guide for Nurse Researchers. 1st Edn., SAGE Publications, Thousand Oaks, ISBN-10: 0761917209, pp: 114.

Datta, B., 1995. How Cairo's Zabbaleen turn rags into riches.. African Business, The Free Library.

Deuffic-Burban, S., M.K. Mohamed, B. Larouze, F. Carrat and A. Valleron, 2006. Expected increase in hepatitis C-related mortality in Egypt due to pre2000 infections. J. Hepatol., 44: 455-461.

El-Jesri, M., 2008. A portrait of poverty. Egypt Today, 29: 108-115.

Emerson, R., R. Fretz and L. Shaw, 1995. Writing Ethnographic Fieldnotes. 1st Edn., University of Chicago Press, Chicago, ISBN-10: 0226206815, pp: 272.

Fahmi, W.S. and K. Sutton, 2006. Cairo's Zabaleen garbage recyclers: Multi-nationals takeover and state relocation plans. Habitat Int., 30: 809-837. DOI: $10.1016 /$ j.habitatint.2005.09.006

Fife, W., 2005. Doing fieldwork: Ethnographic methods for researchin developing countries and beyond. New York: Palgrave Macmillan.

Glasier, A., A. Gulmezoglu, G. Schmid, C. Moreno and P. van Look, 2006. Sexual and reproductive health: A matter of life and death. Lancet, 368: 1595-1607.

Hasan, S., 2003. Christians Versus Muslims in Modern Egypt. 1st End., Oxford University Press, New York, USA.

Hyams, K., M. Mansour, A. Massoud and M.A. Dunn, 1987. Parenteral antischistosomal therapy: Potential risk factor for hepatitis B infection. J. Med. Virol., 23: 109-114.

Frank, C., M. Mohamed, G. Strickland, D. Lavanchy and R. Arthur et al., 2000. The role of parenteral antischistosomal therapy in the spread of hepatitis $\mathrm{C}$ virus in Egypt. Lancet, 355: 887-891. PMID: 10752705 
Ibrahim, S.E., 1996. The Copts of Egypt. 1st Edn., Minority Rights Group, London, ISBN-10: 1897693265, pp: 30.

Kamel, M., S. Rashe, N. Foda, A. Mohie and M. Loutfy, 2003. Gender differences in health care utilization and outcome of respiratory tuberculosis in Alexandria. East. Mediterr. Health J., 9: 741-756. PMID: 15748071

Kamil, J., 2002. Christianity in the Land of the Pharaohs: The Coptic Orthodox Church. 1st Edn., Routledge, New York, USA, ISBN-10: 1136797874, pp: 336.

Kharboush, I.F., A.A. Youssef, M.M. Makhlouf, A.A. Zaghloul and A.A. El-Hamid et al., 2005. Women Health in poor urban settings in Alexandria. J. Egyptian Public Health Assoc., 80: 321-348. PMID: 16922157

Khattab, H., 1992. The silent endurance: Social conditions of women's reproductive health in rural Egypt. Amman: UNICEF, Cairo: The Population Council.

Kovach, G.C., 2003. Out with the trash? Cairo's legendary 'Garbage People' Threatened. Pacific News Service.

Lincoln, Y. and E. Guba, 2011. Paradigmatic Controversies, Contradictions and Emerging Confluences, Revisited. In: The Sage Handbook of Qualitative Research, Denzin, N.K. and Y.S. Lincoln (Eds.), Thousand Oaks: Sage, pp: 97-128.

MacKeen, D., 2003. Bad blood in Egypt.

Mahmood, S., 2012. Religious freedom, the minotiry question and geopolitics in the Middle East. Comparative Studies Society History, 54: 418-446. DOI: $10.1017 / \mathrm{S} 0010417512000096$

Medhat, A., M. Shefata, L. Magdar, N. Mikhail and L. Abdel-Bake et al., 2002. Hepatitis $\mathrm{C}$ in a community in upper Egypt: Risk factors for infection. Am. Society Tropical Med. Hygiene, 66: 633-638.

Nafeh, M., A. Medhat, M. Shehata, N. Mikail and Y. Swifee et al., 2000. Hepatitis C in a community in Upper Egypt Cross sectional survey. Am. J. Tropical Med. Hygiene, 63: 236-241

Palmar, C. and A. Zwi, 1998. Women, health and humanitarian aid in conflict. Disasters, 22: 236-249.

Rao, M.R., A.B. Naficy, M.A. Darwish, N.M. Darwish and E. Schisterman et al., 2002. Further evidence for association of hepatitis $\mathrm{C}$ infection with parenteral schistosomiasis treatment in Egypt. Biomed. Central Infect. Dis., 2: 1-17. PMID: 12464161
Roberts, L. and E. Levitt, 2000. School of Medicine study links hepatitis C spread in Egypt to injection campaigns. University of Maryland Medical Center.

Roudi-Fahimi, F., 2006. Gender and equity in access to health care services in the middle east and North Africa. Population Ref. Bureau.

Russell, G., 2014. Heirs to Forgotten Kingdoms: Journeys into the Disappearing Religions of the Middle East. 1st Edn., Basic Books, New York, ISBN-10: 0465056857, pp: 352.

Sallam, S.A., A. Mahfouz and N. Dabbous, 2001a. Reproductive health of married adolescent women in squatter areas in Alexandria, Egypt. East. Mediterr. Health J., 6: 935-942. PMID: 15332735

Sallam, S.A., A. Mahfouz, N. Dabbous, M. El-Barrawy and M.M. El-Said, 2001b. Reproductive tract infections among married women in Upper Egypt. East. Mediterr. Health J., 7: 139-146. PMID: 12596963

Samaan, M. and S. Sukkary, 1978. The Copts and Muslims. In: Muslim-Christian Conflicts: Economic, Political and Social Origins, Joseph, S. and B. Pillsbury (Eds.), Boulder, CO: Westview Press, pp: 129-150.

Stoszek, S.K., M. Abdel-Hamid, S. Narooz, M. El Daly and D. Saleh et al., 2006. Prevalence of and risk factors for hepatitis C in rural pregnant Egyptian women. Trans. R. Soc. Trop. Med. Hyg., 100: 102-107. DOI: 10.1016/j.trstmh.2005.05.021

Talaat, M., S. Watts, S. Mekheimar, H. Ali and H. Hamed, 2004. The social context of reproductive health in an Egyptian hamlet: A pilot study to identify female genital schistosomiasis. Soc. Sci. Med., 58: 515-524. PMID: 14652048

Tamimi, A.T., 2014. Egypt decides to cut subsidies. Al Monitor.

Thomas, M., A. Youssef, H. Gstrein and P. Strassle, 2006. Copts in Egypt: A Christian Minority under siege. Poland: Vandenhoeck and Ruprecht.

WHO, 2014. Egypt Hepatitis, 2014. regional office fore the Eastern mediterranean report. Cairo, Egypt.

Williamson, K., 2006. Research in constructivist frameworks using ethnographic techniques. Library Trends, 55: 83-101. 